JPL-D- -9870

DE92 016619

\title{
Direct Conversion Technology
}

\section{Progress Report}

\section{Prepared by}

Lloyd H. Back

and by

G. Fabris and M. A. Ryan

Jet Propulsion Laboratory

California Institute of Technology

Report Period: January 1, 1992 to June 30, 1992

July 1992

Sponsored by

Advanced Industrial Concepts Division

Office of Industrial Technology

U.S. Department of Energy

Washington, DC 20585

Through an agreement with

National Aeronautics and

Space Administration

by

Jet Propulsion Laboratory

California Institute of Technology

Pasadena, Califomia 


\section{DISCLAIMER}

This report was prepared as an account of work sponsored by an agency of the United States Government. Neither the United States Government nor any agency Thereof, nor any of their employees, makes any warranty, express or implied, or assumes any legal liability or responsibility for the accuracy, completeness, or usefulness of any information, apparatus, product, or process disclosed, or represents that its use would not infringe privately owned rights. Reference herein to any specific commercial product, process, or service by trade name, trademark, manufacturer, or otherwise does not necessarily constitute or imply its endorsement, recommendation, or favoring by the United States Government or any agency thereof. The views and opinions of authors expressed herein do not necessarily state or reflect those of the United States Government or any agency thereof. 


\section{DISCLAIMER}

Portions of this document may be illegible in electronic image products. Images are produced from the best available original document. 
Prepared by the Jet Propulsion Laboratory, California Institute of Technology, for the U.S. Department of Energy through an agreement with the National Aeronautics and Space Administration.

This report was prepared as an account of work sponsored by an agency of the United States Government. Neither the United States Government nor any agency thereof, nor any of their employees, makes any warranty, express or implied, or assumes any legal liability or responsibility for the accuracy, completeness, or usefulness of any information, apparatus, product, or process disclosed, or represents that its use would not infringe privately owned rights.

Reference therein to any specific commercial product, process, or service by trade name, trademark, manufacturer, or otherwise, does not necessarily constitute or imply its endorsement, recommendation, or favoring by the United States Government or any agency thereof. The views and opinions of authors expressed herein do not necessarily state or reflect those of the United States Government or any agency thereof.

The work reported herein was performed through NASA Task RE-152, Amendment 308, and was sponsored by the U.S. Department of Energy under IAA DE-AI0186CE90237. 


\section{TABLE OF CONTENTS}

A. INTRODUCTION $\ldots \ldots \ldots \ldots \ldots \ldots \ldots \ldots \ldots \ldots \ldots \ldots \ldots$

B. OBJECTIVES $\ldots \ldots \ldots \ldots \ldots \ldots \ldots \ldots \ldots \ldots \ldots \ldots \ldots \ldots$

C. RESEARCH ACTIVITIES $\ldots \ldots \ldots \ldots \ldots \ldots \ldots \ldots \ldots \ldots \ldots$

1. Two-Phase Liquid Metal MHD Electrical Generator (LMMHD) . . . 2

2. Alkali Metal Thermal-to-Electric Converter (AMTEC) $\ldots \ldots \ldots, 10$

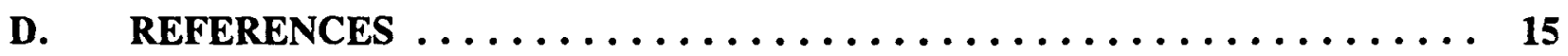

E. PUBLICATIONS AND PRESENTATIONS $\ldots \ldots \ldots \ldots \ldots \ldots \ldots \ldots$

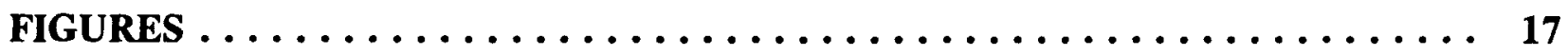

APPENDIX A Paper on Predicted Performance of LMMHD System to be presented at the IECEC Conference, August $1992 \ldots \ldots 18$

APPENDIX B Paper on Thermal Model for AMTEC Cells, January, 1992 . . 19

APPENDIX C AMTEC Papers to be presented at the IECEC Conference August, $1992 \ldots \ldots \ldots \ldots \ldots \ldots \ldots \ldots \ldots \ldots \ldots \ldots .20$

APPENDIX D List of other non-thermal papers on AMTEC Systems . . . . 21

Premoved ard cycled feparatily. 


\section{SUMMARY}

The overall objective of the Direct Conversion Technology task is to develop an experimentally verified technology base for promising direct conversion systems that have potential application for energy conservation in the end-use sectors.

Previous research on the Two-Phase Liquid-Metal MHD Generator (LMMHD) using air, water and a surfactant demonstrated that a high-void-fraction, low-slip bubbly flow pattern is achievable with proper design of a two-phase-flow mixer and application of surface activity of a liquid. Such a two-phase flow pattern is a necessary precondition for subsequent low-slip expansion in a generator. It is expected that the "equivalent turbine efficiency" of a LMMHD generator can be increased roughly two fold over previously experimentally achieved levels. This would be a dramatic improvement which could represent a break-through in commercialization potential of LMMHD energy conversion systems. This could result in substantial energy savings through less fuel use for the same electrical output. The next major task is to explore the characteristics of the expanding bubbly flow in a liquid metal generator. Progress on the construction of the liquid metal blowdown loop to accomplish this along with the design and fabrication of the mixernozzle-generator assembly is given in this report.

Research on the Alkali Metal Thermal-to-Electric Converter (AMTEC) in 1992 has focussed on demonstration of efficiencies greater than $10 \%$ for a full tube, $120 \mathrm{~cm}^{2}$ electrode, AMTEC experiment in the Recirculating Test Cell (RTC), on investigation and optimization of new electrode materials, and on demonstrating electrode stability and performance in long term, high temperature tests in the Vapor Exposure Test Cell 
(VETC). Two RTC experiments have been run since January, 1992. The first was operated at an average of $1100 \mathrm{~K}$ with a platinum-tungsten electrode for 292 hours, and was used to study thermal losses at the condenser surface, power production, sodium recirculation with the electromagnetic pump, and electrode performance. In the second, an efficiency of $10.2 \%$ was measured under load with a platinum-tungsten electrode. The thermal performance of both experiments was fully characterized; the improvement in the second RTC experiment is attributed to lowered thermal losses through use of a multifoil heat shield and to lowered series resistance (electrical) in the electrode + current collection network.

Work which is specifically funded under the DOE-AICD program is thermal characterization and analysis of an operating AMTEC Cell, the RTC. The work includes determination of the emissivity of electrodes and of the condenser under operating conditions, and improvement in the condenser and/or heat shield in the RTC. Use of a heat shield in RTC tests last year resulted in significantly lower radiative heat loss at the condenser; work this year has continued by analysis of the effect of heat shields, including different types of shields. The emissivity of PtW thin films was measured in vacuum in a cell designed and built for that purpose. Related work analyzed a new electrode material, platinum-tungsten, to find the optimum $\mathrm{Pt} / \mathrm{W}$ ratio.

Work which is funded by other sponsors involves studies of electrode life and performance, and cell efficiency. These studies include investigations of electrode materials and current collection, braze seals, and high efficiency continuous operation tests. There is also a research effort in design of alternative geometries for AMTEC cells and in 
fabrication of potassium and sodium $\beta$ "-alumina in geometries which are not commercially available.

Electrode performance modelling and elucidation of processes occurring at the AMTEC electrode, specifically sodium transport, have also been goals of AMTEC research this year. Significant progress has been made in electrode performance studies. The Vapor Exposure Test Cell (VETC) has been used to study the effects of high temperature and sodium vapor on new electrode materials, as well as to study the effects of electrode and current collecting materials on each other. Platinum/tungsten alloy thin film electrodes have been tested in VETC with very promising results. A life model based on sintering of electrode material has been developed and used with data from VETC and AMTEC tests to predict operating lifetimes of various electrode materials. 


\section{A. INTRODUCTION}

A comprehensive introduction to the Direct Conversion Technologies activities appears in Ref. 1. Descriptions of various direct thermal-to-electric conversion systems appear in Refs. 1-4. The systems described are: Alkali Metal Thermal-to-Electric Converter (AMTEC), Two-Phase Liquid Metal MHD (LMMHD) Electric Generator, Thermoelectric, Thermionic, Pyroelectric, Thermoacoustic, Thermoelastic (Nitinol heat engine), Thermophotovoltaic, and a variety of Thermomagnetic concepts. Assessments of these systems have been made and research needs have been identified for systems which, if developed, appear to show promise for energy conservation in the end-use sector. Initially, two systems were selected for exploratory research and advanced development. These are LMMHD and AMTEC. This report describes progress that has been made during the first six months of CY 1992 on research activities associated with these two systems.

\section{B. OBJECTIVES}

The overall objective of the direct conversion technology task is to develop an experimentally verified technology base for promising direct conversion systems that have potential application for energy conservation in the end-use sectors. Specific objectives are:

1. For the Two-Phase Liquid-Metal MHD Electric Generator 1) Continue the construction of the liquid metal blowdown loop to investigate effects of mixer and surfactants to reduce the slip between gas bubbles and the liquid metal in the 
generator in order to improve the efficiency, 2) design and fabricate the mixernozzle-generator assembly.

2. For the Alkali Metal Thermal-to-Electric Converter characterize 1) the thermal properties of AMTEC cells utilizing large (full tube) area electrodes, and 2) the temperature gradients within the cell which are important for the fundamental understanding of device performance and may significantly affect stresses within the device.

C. RESEARCH ACTIVITIES

1. Two-Phase Liquid Metal MHD Electrical Generator (LMMHD)

a) Computer Analysis of Performance of LMMHD Generator

This analysis has now been finalized. Figure 1 gives three shapes of the LMMHD generator analyzed. These three shapes were discussed in more detail in the last Annual Report. The final shape of the LMMHD generator selected for manufacturing is one with the radius of curvature of the electrode of $R=150 \mathrm{~mm}$ in the inlet part of the generator. Following the circular arc expansion, the distance between the electrodes increases linearly toward the end of the generator. From the inlet to the outlet of the generator the distance between the electrodes increase ten fold, i.e., from 20 to $200 \mathrm{~mm}$. Distance between the insulated walls increases two fold, linearly from 5 to $10 \mathrm{~mm}$. Predicted performance of such a generator for no-slip conditions was discussed in the last Annual Report; the paper is included herein in Appendix A. 


\section{b) Liquid Metal MHD Blowdown Loop}

Construction of the Blowdown Loop has continued. The complete schematic of the loop is given on Fig. 2. Basically almost all of the main components have been secured and installed. These include the magnet, high pressure 60 gallon liquid metal (NaK) supply tank, and low pressure 60 gallon liquid metal receiver tank. A commercial twophase flow swirl separator has been purchased and installed. A 55 gallon stainless steel $\mathrm{N}_{2}$ exhaust drum has been obtained. The drum has been located on the top of the concrete roof. The 3 inch nitrogen gas exhaust pipeline has been installed. The 3 inch pipeline terminates in the 55 gallon drum. A conical funnel cover for the drum was manufactured and installed. A conductivity probe consisting of two closely spaced (3/8 of an inch) stainless steel screens was placed at the bottom of the barrel. The purpose of this conductivity probe is to detect any NaK carryover in the nitrogen gas exhaust. It is expected that $\mathrm{NaK}$ oxides would slowly build up at the bottom of barrel and trigger the conductivity probe. The procedure would be then to clean the bottom of the barrel. If there is an inadvertent, more rapid carry over of $\mathrm{NaK}$ with the exhaust gas, then the conductivity probe would give prompt indication of it and the experimental run would be terminated promptly. To increase redundancy of this safety feature, one more conductivity probe will be installed in the 3 inch $\mathrm{N}_{2}$ exhaust pipe just upstream of the exhaust control valve PV\#4.

All four pneumatic control valves have been acquired and installed. In the pneumatic control for $\mathrm{NaK}(\mathrm{PV \# 2})$ the teflon seals on the seat and the packaging were replaced by neoprene parts made at JPL. The reason for this is that teflon is not 
chemically compatible with $\mathrm{NaK}$.

Two pressure regulators (PR \#1 and PR \#2) were acquired and installed as well. Three pressure relief valves were also acquired and installed. Two of them, RV\#1 and

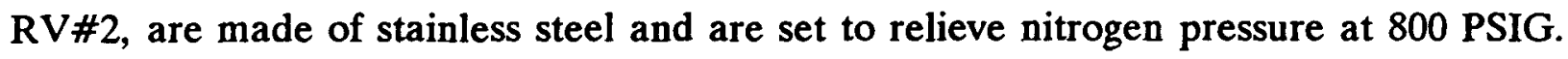
One, RV\#3, carbon steel two inch diameter relief valve was set at 25 PSIG and installed in the three inch nitrogen exhaust line.

A NaK filter, actually strainer, with a fine mesh of 100 openings per inch has been acquired. A turbine flowmeter for the $\mathrm{NaK}$ has been installed. An orifice flowmeter for the nitrogen has been replaced by a turbine flowmeter so that a wide range of flow rates can be covered with the same instrument. The control panel for the blowdown loop has been designed as indicated on Fig. 3. It includes a simplified schematic of the loop which facilitates understanding of the key control features. These include key pressures such as the NaK supply tank, the supply of nitrogen, and the exhaust nitrogen gas downstream of the MHD generator. Other key parameters which are to be controlled and monitored during the experiment are flow rates of the liquid metal, $\mathrm{NaK}$, and gaseous nitrogen $\mathrm{N}_{2}$. The key pressures and the flow rates will be controlled using four pneumatic valves. These four valves will be operated remotely from the control panel.

There are a total of 27 pressure measuring locations as indicated in Fig. 2. A few key pressures will be displayed on the control panel. It would be too expensive and complex to provide pressure transducers for all of the pressure measuring locations. For this reason, a Scanivalve model $48 \mathrm{JM}$ was purchased. This scanivalve can rapidly multiplex (scan) through 48 pressure measuring lines connecting them to a single pressure transducer. 
An electrical signal generated by the scanivalve indicates which pressure tap is being read at the time. The scanivalve purchased is made to be compatible with $\mathrm{NaK}$. However, as a precaution against damaging or plugging of the scanivalve, all the pressure lines in the scanivalve region will be filled with an instrument oil such as heavy silicon oil.

Fig. 4 shows the floor plan of the Liquid Metal MHD Blowdown Loop in the building. The loop will be operated from the Control Panel which is in a separate control room. The experimental room and control room are separated by a concrete wall which contains small safety windows.

An X-ray system has already been installed in the experimental room as indicated in Fig. 4.

c) Two-Phase Flow Liquid Metal and Gas Mixer and MHD Generator Section

Figure 5 is a schematic of the test section for the Liquid Metal MHD Blowdown Loop. Full engineering drawings of the two-phase flow mixer have been developed. They have been revised a few times to facilitate manufacturing. These drawings are quite extensive and detailed. It would take too much space to try to include these drawings in this report. They deal with many design and manufacturing issues.

The basic design goal of the two-phase flow mixer is to create an almost completely homogenous bubbly flow pattern of uniform void fraction and velocity profiles. Orientation of the mixer is such that the flow is upward. Liquid metal, $\mathrm{NaK}$, is introduced into the flow straightener section. 
The cross-sectional area of the flow straightener and the mixer is $3 \times 3$ inches. The liquid metal flows first through a uniform perforated plate. The function of the plate is to generate mid-size energetic eddies which greatly enhance mixing and equalize velocity across the whole cross-section. The velocity profile of this flow is further uniformized by passing the liquid metal through a honeycomb with cells of a quarter of an inch. The honeycomb completely damps out turbulence in the flow. The result is a laminar flow of "plug" type uniform velocity. This flow enters the mixing section along the sides of three gas injection elements. Each injection element has two $3 \times 10$ inch porous plates made of stainless steel with 0.5 micron pores. Through these plates nitrogen gas is injected at a low velocity into the flowing liquid metal. Nitrogen injection generates a multitude of small bubbles in an organized way with minimum disturbance to the flow. Each of the injection elements has a two dimensional wedge shaped trailing edge. A favorable pressure gradient along the flow in the region of the trailing edges was achieved by contracting the cross-section area available to the flow. The favorable pressure gradient ensures no two-phase flow separation at the trailing edges of the injection elements. The nozzle is designed to be made from a single stainless steel piece by electro discharge machining. At the exit of the nozzle the cross-sectional area is $20 \times 5 \mathrm{~mm}$. Along the contraction the flow accelerates substantially, there is large pressure decrease, and there is a substantial increase in void fraction due to expansion of the bubbles. This rapid expansion process will help to stabilize the bubbly flow pattern due to stretching of the twophase interface and insure substantial heat transfer from the liquid to the gas. 
Care is taken in the design not to overpressurize the porous plates because they are held on a frame by a thin laser weld. Overpressurization is avoided by having a pressure relief valve in the nitrogen supply line to the mixer. Pressures of the $\mathrm{N}_{2}$ gas and the liquid metal at the entrance to the mixer are sensed. If the gas pressure is higher than the liquid pressure by more than 20 PSID, then the relief valve opens and relieves excess gas flow into the flow straightener section just upstream of the mixer. It is expected that the condition of potential overpressurization of the injection elements would last only for a few seconds during the start up of the experiments. Once approximate steady state flow rates are approached, the pressure difference across the perforated plate will be at most only about 3 PSID. Figure 5 does not show this pressure relief system.

Figure 6 is a schematic showing one of the gas injection elements. The thickness of the element at its leading edge is $3 / 4$ of an inch. The thickness of the element at the downstream end of the gas injection region is $3 / 8$ of an inch. In this way more crosssectional area is provided for the two-phase flow as more gas is injected along the element. Due to very low velocities, about $1 \mathrm{~m} / \mathrm{s}$, and the vertical upward orientation of the mixer, this region will still have a favorable pressure gradient along the flow thus preventing twophase flow separation. The trailing wedges of the injection elements are made of fiber glass which is electrically nonconductive. In this way, electrical leakage currents in the generator end region are decreased. The whole nozzle will be coated on the inside by an insulating material. The reason is again to minimize the end region leakage currents.

The flow straightener, the mixer and the nozzle are being manufactured. The manufacturing is funded by a private company, so that DOE funding is saved for building 
other parts of the loop.

Detailed engineering design of the experimental LMMHD generator has been completed. The drawings had to be revised a few times to fit measurements and manufacturing and other requirements. These drawings are even more complex than those for the mixer and the nozzle. The drawings are not included in this report. The basic shape of the LMMHD generator is shown in Fig. 4, and was mentioned earlier. It was decided to make the two electrodes of aluminum instead of copper. The reason is decreased cost, easier machining, lower weight and considerably better transparency properties to the $\mathrm{x}$-rays. The two other walls, which are approximately perpendicular to the magnetic field, will be made of an electrically insulating material. These two walls are straight and flat. They will be formed by pouring and curing hard neoprene in place. The structural strength of these two insulating walls is provided by back-up compensating plates which will be made out of aluminum. These plates are called compensating because they return electrical current, generated in the LMMHD generator, back in an opposite direction within the magnet poles. In this way, compensation of the current induced magnetic field is accomplished.

The LMMHD generator is instrumented with eleven pressure taps spaced approximately every inch along the generator. The pressure taps are all located in the positive electrode (one which connects to the compensating plates). Each of the two electrodes has nine "x-ray windows". A detail of an x-ray window is given in Fig. 7. In the plane perpendicular to the applied magnetic field, the electrodes are approximately one inch thick. At the "x-ray windows" the thickness of the electrodes is decreased to $3 / 16$ of 
an inch. The width of these deep window indentations is $3 / 8$ of an inch. The span of the windows is wider than the local span of the LMMHD generator channel opening, i.e. the span between the insulating walls. The local span of the electrodes is of course wider than the span of the $x$-ray windows. The purpose of the $x$-ray windows is to allow most of the $\mathrm{x}$-rays to be transmitted through the electrodes and the two-phase flow. In this way the accuracy of measurements of void fractions is greatly increased. Measurement of the void fractions is the key in gaining insight into internal phenomena in the generator such as velocity slip between the two fluid phases.

Current is taken out of the generator by attaching bus bars to the negative electrode and on the two compensating plates which in turn are in direct electrical contact with the positive electrode.

Just downstream of the generator is an "exit piece". This piece is to be made out of stainless steel. It transizes the flow cross-sectional area from a rectangular shape at the generator exit to a three inch round pipe shape. The entire internal area of the exit piece will be coated by an insulating material. The purpose is to minimize exit region end losses due to leakage of current.

After a couple of iterative improvements in the LMMHD generator design, a manufacturing estimate was obtained from the JPL Fabrication Shop. Unfortunately, the estimate was too high with respect to available budget. Outside manufacturing firms were contacted and a considerably less expensive manufacturing estimate was received. A procurement requisition was written to manufacture the LMMHD generator in a shop outside of JPL. The purchase order has been issued and manufacturing has been initiated. 


\section{d. Planned Work for Rest of CY 1992}

It is expected that the flow straightener, mixer and the nozzle sections for the Blowdown Loop will be manufactured by September 1992. Machining of the experimental LMMHD generator is expected to be completed by the end of September. Following this the insulating coatings would be applied to the inside of the nozzle and the exit (from LMMHD generator) piece. Insulating coatings will be also applied on a few inches at the inlet and outlet of each electrode. At the same time two insulating walls along the whole generator will be made by pouring and curing hard neoprene on the aluminum compensating plates while the electrodes are in place. Making of all internal insulation coatings and walls is expected to be finished in October.

In parallel with this, construction of the control panel will be initiated. It is expected that the panel will done by the end of September.

After this, the whole test section will be assembled in the loop connecting into the main piping. This should be accomplished in November.

After the test section has been assembled in the loop, work will start on installing the pressure measuring tubing and other instrumentation lines and control pneumatic tubing and electrical signal lines.

Experimental test strategy and plans will be also developed.

\section{Alkali Metal Thermal-to-Electric Converter (AMTEC)}

The first Recirculating Test Cell (RTC) experiment operated this year used a $\mathrm{Pt}_{2.5} \mathrm{~W}$, $120 \mathrm{~cm}^{2}$ electrode and a new type of heat shield. The heat shield was "louvered"; it was 
made from molybdenum mesh with strips of molybdenum foil spaced around the mesh. The purpose of using mesh was to improved sodium transport away from the electrode, and thus to decrease $G$, the morphology factor, which is a measure of resistance to sodium flow. It was expected that sodium would fill the holes in the mesh, making a highly reflective heat shield which would transport sodium away. Performance of this cell was below expectations. The measured efficiency was $6.7 \%$ under load. $G$ was not reduced by the mesh heat shield, and thermal losses were higher than expected. G is generally expected to be $\sim 100$ for good sodium flow, in this experiment the average $G$ was $\sim 150$. The thermal loss was $1.59 \mathrm{~W} / \mathrm{cm}^{2}$ at open circuit. Conductive heat loss was $22 \mathrm{~W}$ at high temperature; this loss was along the electrical leads $(13.2 \mathrm{~W})$ with the remainder lost through the tube support and the argon purge over the liquid sodium.

The second RTC experiment run this year took advantage of the information gained from analysis of the first experiment, and efficiency was significantly improved. This experiment used a $120 \mathrm{~cm}^{2} \mathrm{Pt}_{3} \mathrm{~W}$ electrode. It ran 33 hours and the measured efficiency was $10.2 \%$ under load. The major innovation in this experiment was the use of a multifoil heat shield. Six layers of molybdenum foil were used in place of the louvered shield used in the previous experiment. A second innovation was reduction of the contact resistance by sputtering a thin layer of platinum over the current collecting mesh which is tied on over the electrode. The thermal loss was $0.82 \mathrm{~W} / \mathrm{cm}^{2}$, a reduction of nearly $50 \%$ from the previous test. Sodium flow was, however impeded by the heat shield; $G$ increased from $\sim 150$ in the previous experiment to $>250$ for this experiment. Additional improvement was found in the series resistance by sputtering platinum on the mesh and by adding more 
bus bars. The thermal cost of the additional bus bars was $1-2 \mathrm{~W}$ in conductive loss; total conductive loss in this experiment was $\sim 25 \mathrm{~W}$.

Data for both RTC experiments are given in Table 1.

Table 1: Performance of Two Recirculating Test Cells in 1992

\begin{tabular}{|c|c|c|c|c|c|}
\hline \hline & $\begin{array}{c}\text { Thermal loss } \\
\left(\mathrm{W} / \mathrm{cm}^{2}\right)\end{array}$ & $\begin{array}{c}\text { Conductive } \\
\text { loss (W) }\end{array}$ & $\mathrm{G}$ & $\begin{array}{c}\mathrm{R}_{\mathrm{s}} \\
\left(\Omega-\mathrm{cm}^{2}\right)\end{array}$ & Efficiency \\
\hline RTC 1 & 1.59 & 22 & 150 & .67 & $6.7 \%$ \\
RTC 2 & 0.82 & 25 & $>250$ & .33 & $10.2 \%$ \\
\hline
\end{tabular}

Understanding of the thermal characteristics of an AMTEC cell will require that the electrode operating temperature and the emissivities of the heat shield material, the $\beta^{\prime \prime}-$ alumina solid electrolyte (BASE), the electrode and the condenser be known. The emissivities of a $\mathrm{Pt}_{2.5} \mathrm{~W}$ electrode, Mo foil, BASE and PtW electrode with molybdenum screen tied on were measured at $1080 \mathrm{~K}$ under vacuum by optical pyrometry in a cell constructed for this purpose. This measurement gave emissivity values of $.53, .47, .44$ and .59 , respectively. The emissivities of these materials over a range from $850-1200 \mathrm{~K}$ will be measured in a new cell, both under vacuum and in sodium atmosphere. The electrode operating temperature will be measured directly, using optical pyrometry and the measured emissivity.

Complete analysis of thermal characteristics of the RTC system requires a model with distributed heat input. Such a model is under development. The simple model now used over estimates conductive losses. This over estimation results in underestimation of 
the radiation losses (calculated as the difference between the total heat in and the conductive loss), as well as the condenser emissivities.

\section{b. Electrode Life and Performance Studies and Modelling}

A life model for AMTEC electrodes has been developed, using the measured sintering rates and fitting the fall in exchange current over time to the sintering behavior. Using this model, the operable lifetime for rhodium-tungsten electrodes is predicted to be in excess of 25 years. The operable lifetime of platinum-tungsten electrodes is predicted to be 5 - 15 years, depending on the presence of underlying current collection grids made of molybdenum films. (The presence of Mo increases the sintering rate).

A long term ( 3000 hours) experiment in the Vapor Exposure Test Cell (VETC) has been run to test the performance of platinum/tungsten alloy electrodes and to determine the optimum $\mathrm{Pt} / \mathrm{W}$ ratio. Electrodes with $\mathrm{Pt} / \mathrm{W}$ ratios ranging from 1.8 to 6 were tested. It was found that all compositions have very good sodium transport, but that the best performing $\mathrm{Pt} / \mathrm{W}$ ratio is 3.5. $\mathrm{Pt}_{3.5} \mathrm{~W}$ electrodes are the best performing electrodes yet tested in the AMTEC laboratory. This composition will be used in future experiments.

VETC experimental data are analyzed for performance parameters such as exchange current, morphology factor $(G)$, electrode resistance and power production. Models to extract kinetic and transport information from VETC data have been developed, and are used to compare electrode compositions and arrangements. In addition, a model for a correlation of electrode morphology with electrochemical data has been developed. 


\section{c. Alternative AMTEC Systems}

Potassium AMTEC's were proposed last year, and work continues in this field. The results of this work show the possibility of building an AMTEC using potassium as the working fluid, which will allow operation at lower temperature than with sodium. Work continues in alternative systems in an effort to make flat plates of sodium and potassium $\beta$ "-alumina by tape-casting, in order to build systems with alternative configurations. 


\section{REFERENCES}

1. P.F. Massier, C.P. Bankston, G. Fabris and L.D. Kirol, "ECUT Direct Conversion Technology Annual Summary Report CY 1988", JPL D-5698, Jet Propulsion Laboratory Pasadena, California, December 1, 1988.

2. P.F. Massier, "ECUT Direct Conversion Technology Annual Summary Report CY 1987", D-4856, Jet Propulsion Laboratory, Pasadena, California, January 7, 1988.

3. P.F. Massier, "ECUT Direct Conversion Technology Project Annual Report CY 1986", JPL D-3707, Jet Propulsion Laboratory, Pasadena, California, January 15, 1987.

4. P.F. Massier, C.P. Bankston, R. Williams, M. Underwood, B. Jefferies-Nakamura, and G. Fabris, "ECUT Direct Conversion Technology Annual Summary Report CY 1989," JPL D-6846, Jet Propulsion Laboratory, Pasadena, California, December 4, 1989. 


\section{E. PUBLICATIONS AND PRESENTATIONS}

A paper titled "Prediction of Performance of Two-Phase Flow Nozzle and Liquid Metal Magnetohydrodynamic (LMMHD) Generator for No Slip Condition" will be presented at the 27th Intersociety Energy Conversion Engineering Conference (IECEC) to be held in San Diego, California, August, 1992. This paper will be published in the proceedings volume and was submitted for publication in the Energy Conversion and Management Journal. This paper appears in Appendix A.

A paper discussing a distributed elements thermal model for analysis of AMTEC cells was presented at the Ninth Symposium on Space Nuclear Power Systems in January, 1992, and has been published in a proceedings volume. This paper, "Thermal Modeling of AMTEC Recirculating Cell", appears in Appendix B.

Four papers discussing thermal aspects of AMTEC operation will be presented at the 27th Intersociety Energy Conversion Engineering Conference and will be published in a proceedings volume. These papers appear in Appendix C. Two papers discuss cell and electrode performance, including thermal data; they are "Activated Transport in AMTEC Electrodes" and "Efficiency of an AMTEC Recirculating Test Cell; Experiments and Projections". A further paper on the thermal model of the AMTEC cell, "Thermal Modeling of an AMTEC Recirculating Cell", and a paper discussing the thermodynamics of the cell, "A Reversible Thermodynamic Cycle for AMTEC Power Conversion" will also be presented.

Other papers and presentations made by members of the AMTEC team in 1992 and which do not specifically refer to thermal analysis are listed in Appendix D. 


\section{LIST OF FIGURES}

1. Distance between the Electrodes for Three LMMHD Generators Tested by the Computer Prediction Code.

2. Complete Schematic of the Liquid Metal MHD Blowdown Loop.

3. Schematic of the Control Panel for the LMMHD Blowdown Loop.

4. Floor Plan of the Liquid Metal MHD Blowdown Loop.

5. Test Section for the Two-Phase Liquid Metal MHD Blowdown Loop.

6. Schematic of the Gas Injection Element for LMMHD Blowdown Loop.

7. Detail of an X-Ray Window. 


\section{LMMHD GENERATOR SHAPES}

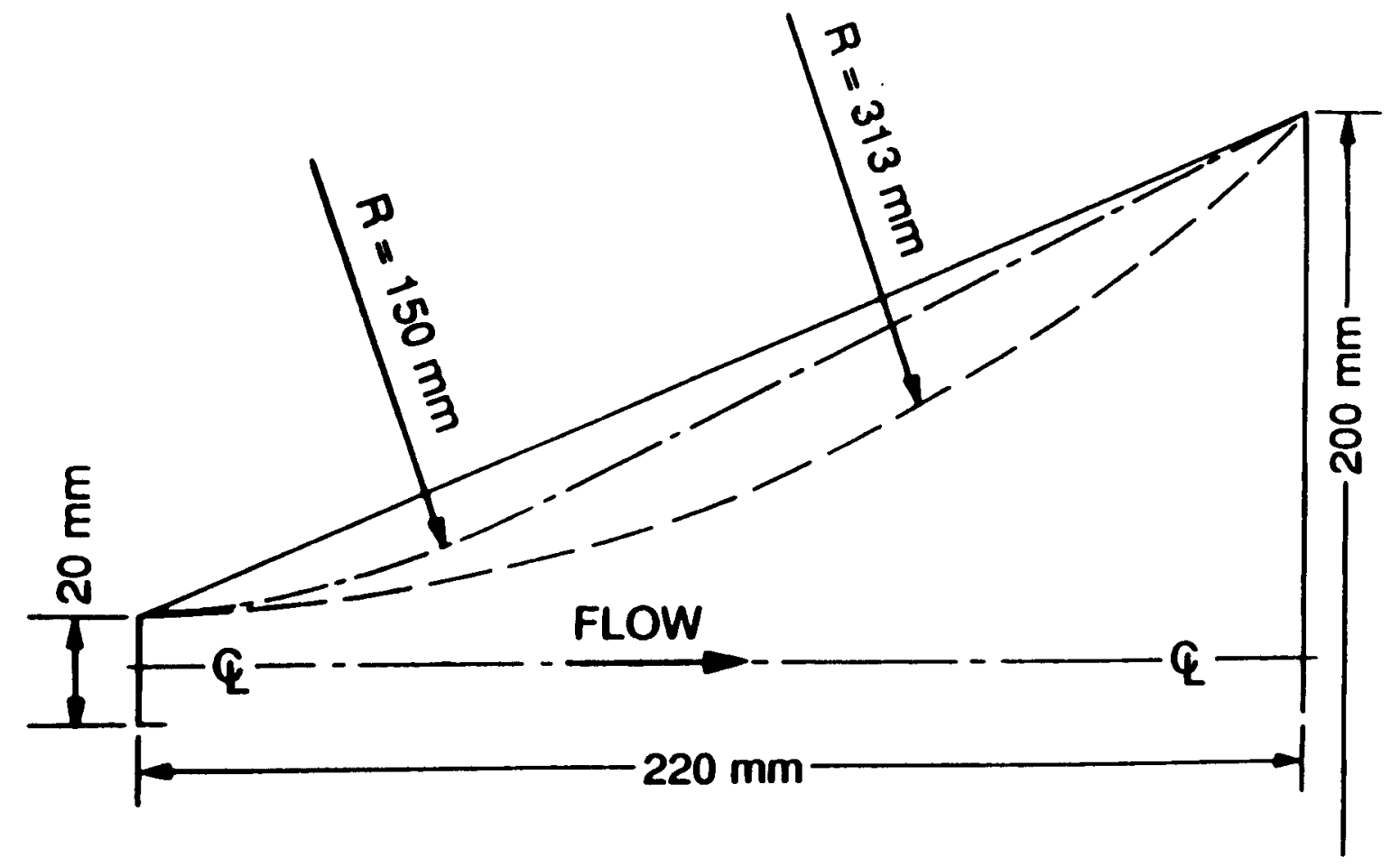

Figure 1.

Distance between the Electrodes for Three LMMHD Generators Tested by the Computer Prediction Code. 


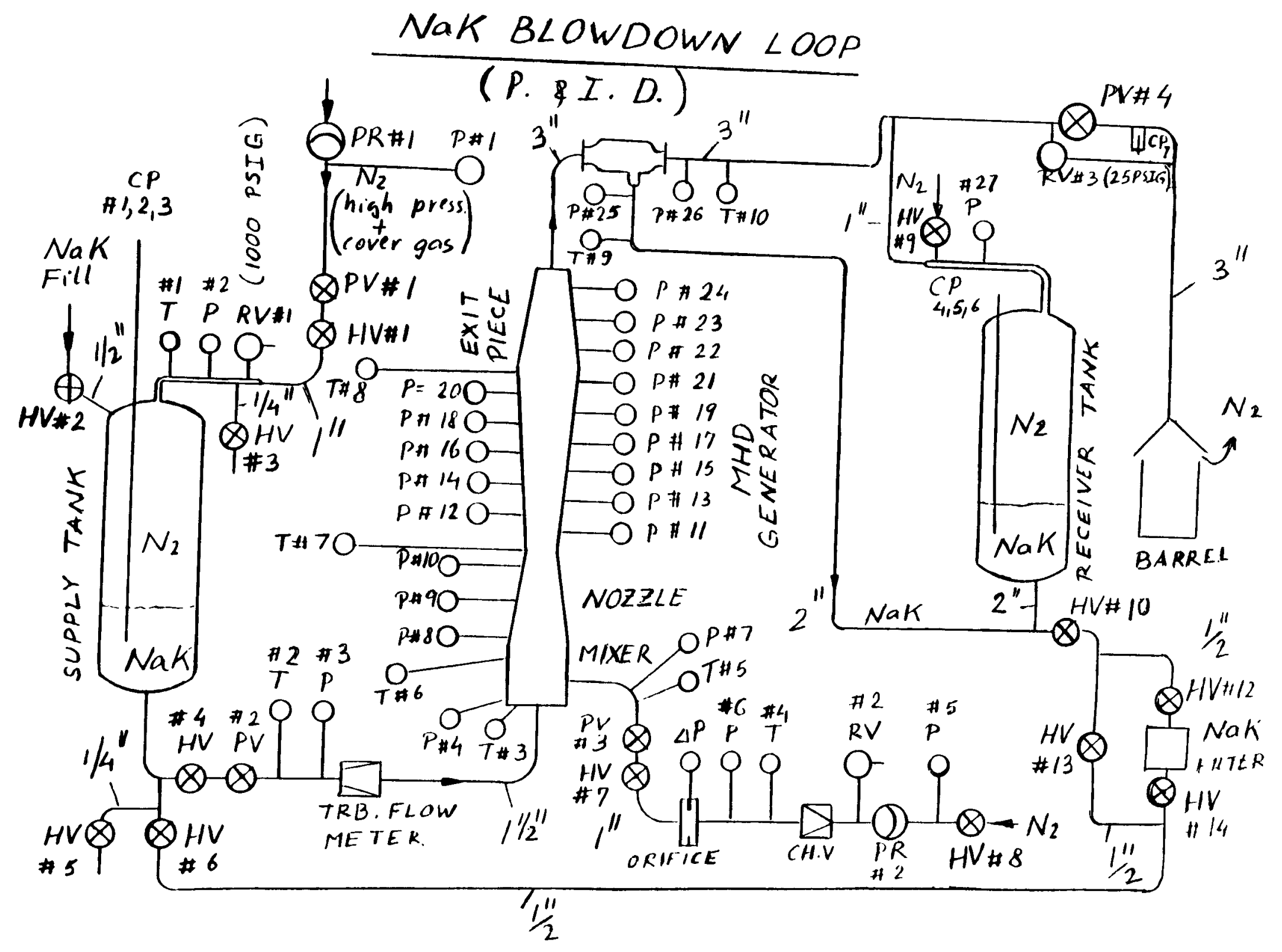

Figure 2.

Complete Schematic of the Liquid Metal MHD Blowdown Loop. 
CONTROL PANEL FOR MHD LOOP

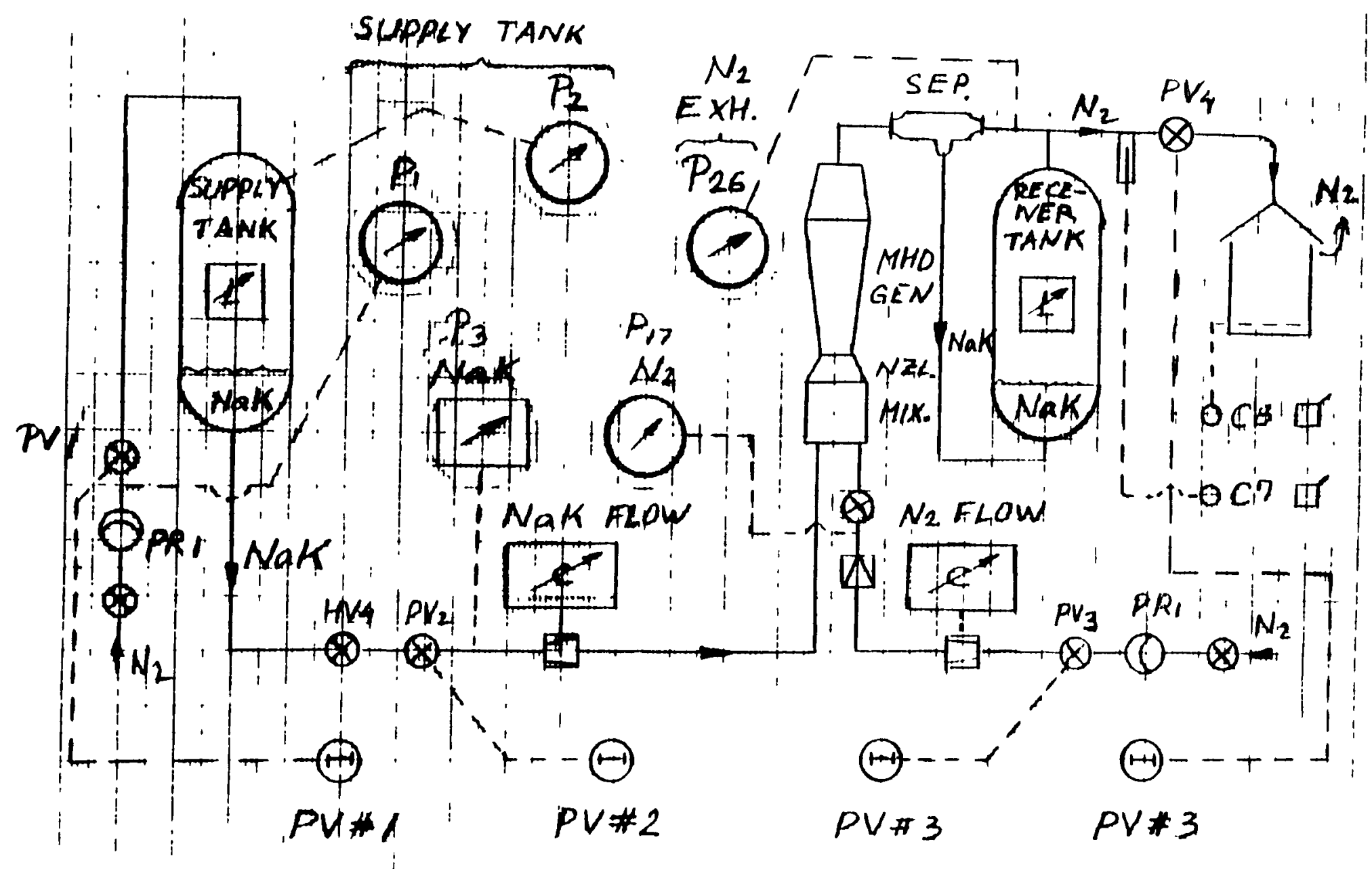

Figure 3.

Schematic of the Control Panel for the LMMHD Blowdown Loop. 


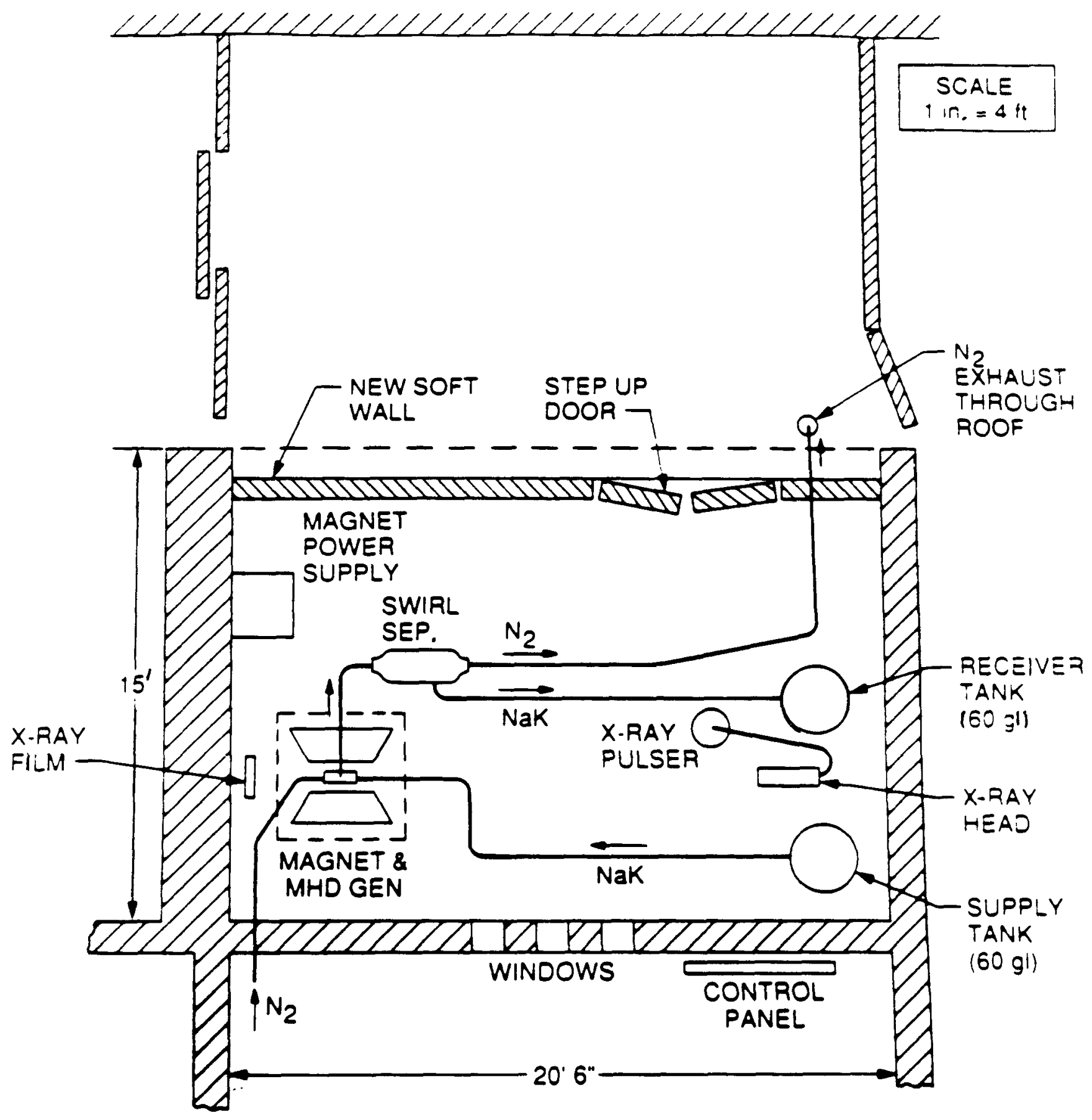

Figure 4.

Floor Plan of the Liquid Metal MHD Blowdown Loop. 

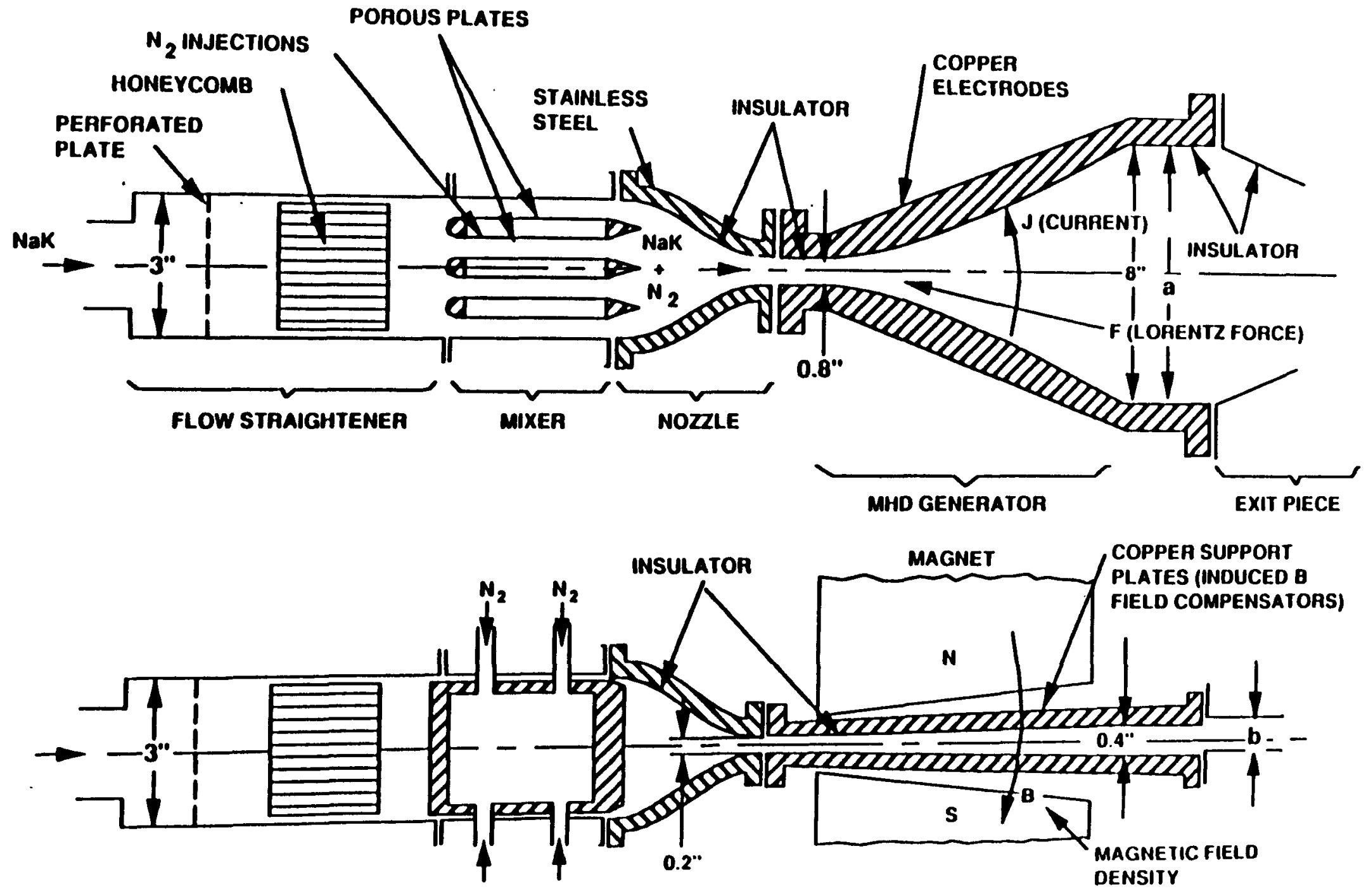

Figure 5.

Test Section for the Two-Phase Liquid Metal MHD Blowdown Loop. 
GAS INJECTION ELEMENT$$
S C A L E \quad 1: 1
$$

Material : stainless steel

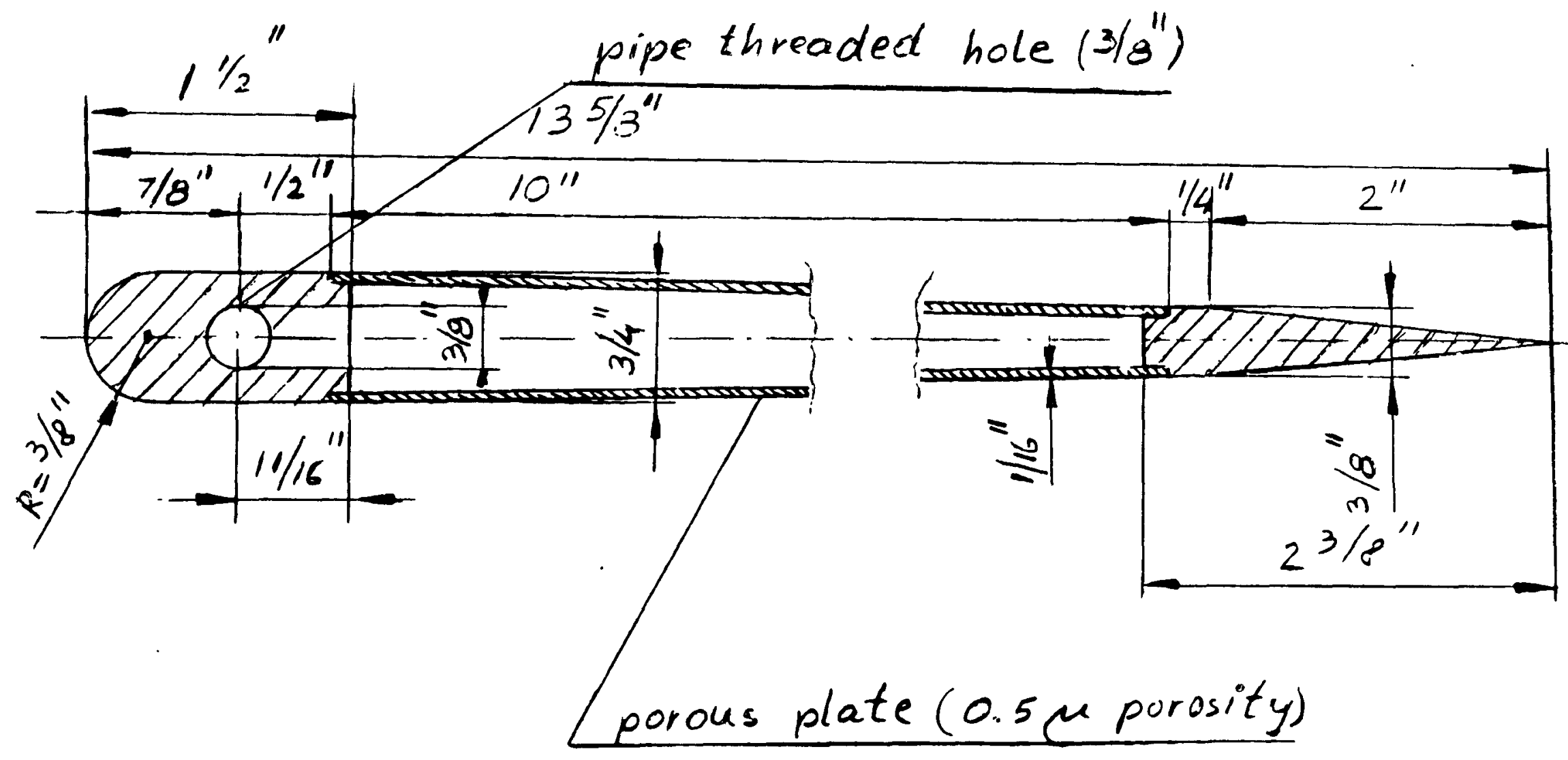

Figure 6. Schematic of the Gas Injection Element for LMMHD Blowdown. 


\section{DETAIL OF X-RAY WINDOW}
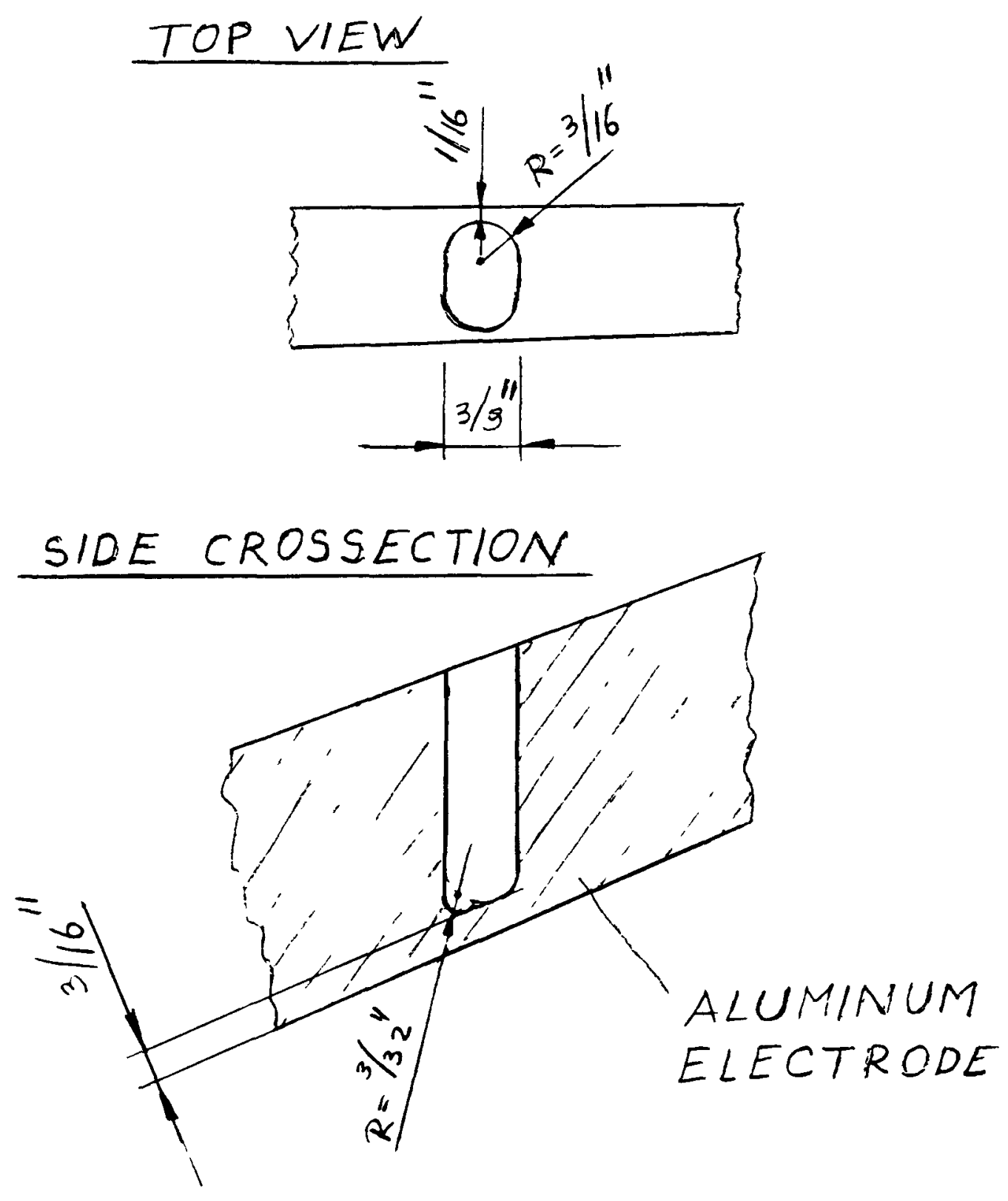

Figure 7.

Detail of an X-Ray Window. 


\section{APPENDIX D}

Other Presentations and Publications in 1992

Journal publications:

"Electrode Performance Parameters for a Radioisotope Powered AMTEC for Space Power Applications", M.L. Underwood, D. O'Connor, R.M. Williams, B. Jeffries-Nakamura, M.A. Ryan and C.P. Bankston Journal of Power and Propulsion, 8, (1992)

"Thermal-to-Electric Converter with Greater Power Density", R.M. Williams, J.W. Suitor, B. Jeffries-Nakamura, M.L. Underwood, M.A. Ryan and D. O'Connor NASA Tech Briefs, 88, May, 1992.

Presented at the Ninth Symposium on Space Nuclear Power Systems, January, 1992, and published in a Proceedings Volume.

"An AMTEC Vapor-Vapor, Series Connected Cell" by M.L. Underwood, R.M. Williams, M.A. Ryan, B. Jeffries-Nakamura and D. O'Connor

Presented at the 181st Meeting of the Electrochemical Society, May, 1992.

"Platinum-Tungsten and Rhodium-Tungsten Alloys for AMTEC Electrodes" by M.A. Ryan, R.M. Williams, B. Jeffries-Nakamura, D. O'Connor and M.L. Underwood.

To be presented at the 27th Intersociety Energy Conversion Engineering Conference August 1992, and to be published in the proceedings volume.

"Advances in Materials and Current Collecting Networks for AMTEC Electrodes", by M.A. Ryan, B. Jeffries-Nakamura, R.M. Williams, M.L. nUnderwood, D. O'Connor and S. Kikkert. 